University of Nebraska - Lincoln

DigitalCommons@University of Nebraska - Lincoln

2012

\title{
Combined effects of plant competition and insect herbivory hinder invasiveness of an introduced thistle
}

Tomomi Suwa

Michigan State University, suwatomo@msu.edu

Svata M. Louda

University of Nebraska - Lincoln, slouda1@unl.edu

Follow this and additional works at: https://digitalcommons.unl.edu/bioscilouda

Suwa, Tomomi and Louda, Svata M., "Combined effects of plant competition and insect herbivory hinder invasiveness of an introduced thistle" (2012). Svata M. Louda Publications. 29.

https://digitalcommons.unl.edu/bioscilouda/29

This Article is brought to you for free and open access by the Papers in the Biological Sciences at DigitalCommons@University of Nebraska - Lincoln. It has been accepted for inclusion in Svata M. Louda Publications by an authorized administrator of DigitalCommons@University of Nebraska - Lincoln. 


\title{
Combined effects of plant competition and insect herbivory hinder invasiveness of an introduced thistle
}

\author{
Tomomi Suwa ${ }^{1,2}$ and Svata M. Louda ${ }^{1}$
}

1. School of Biological Sciences, University of Nebraska-Lincoln, Lincoln, NE 68588, USA

2. Present address: Department of Plant Biology, Ecology, Evolutionary Biology and Behavior Program, and W. K. Kellogg

Biological Station, Michigan State University, Hickory Corners, MI 49060, USA

Corresponding author - Tomomi Suwa, email suwatomo@msu.edu

\begin{abstract}
The biotic resistance hypothesis is a dominant paradigm for why some introduced species fail to become invasive in novel environments. However, predictions of this hypothesis require further empirical field tests. Here, we focus on evaluating two biotic factors known to severely limit plants, interspecific competition and insect herbivory, as mechanisms of biotic resistance. We experimentally evaluated the independent and combined effects of three levels of competition by tallgrass prairie vegetation and two levels of herbivory by native insects on seedling regeneration, size, and subsequent flowering of the Eurasian Cirsium vulgare, a known invasive species elsewhere, and compared its responses to those of the ecologically similar and co-occurring native congener C. altissimum. Seedling emergence of $C$. vulgare was greater than that of C. altissimum, and that emergence was reduced by the highest level of interspecific competition. Insect leaf herbivory was also greater on C. vulgare than on C. altissimum at all levels of competition. Herbivory on seedlings dramatically decreased the proportion of $C$. vulgare producing flower heads at all competition levels, but especially at the high competition level. Competition and herbivory interacted to significantly decrease plant survival and biomass, especially for C. vulgare. Thus, both competition and herbivory limited regeneration of both thistles, but their effects on seedling emergence, survival, size and subsequent reproduction were greater for $C$. vulgare than for $C$. altissimum. These results help explain the unexpectedly low abundance recorded for $C$. vulgare in western tallgrass prairie, and also provide strong support for the biotic resistance hypothesis.
\end{abstract}

Keywords: biotic resistance, bull thistle, spear thistle, Cirsium vulgare, tall thistle, Cirsium altissimum, exotic plants, insect herbivory, insect-plant interactions, invasive species, seedling regeneration

Supplementary material for this article is presented following the References.

\section{Introduction}

Most introduced species fail to colonize, establish or spread in novel environments, while a few species become widely invasive (Williamson 1996). Thus, a central objective in invasion ecology is to understand factors that limit invasiveness. The biotic resistance hypothesis, first proposed by Elton (1958), posits that strong interactions between the native community and introduced species can limit the introduction, establishment, and spread of invasive species. However, predictions emerging from this descriptive hypothesis require further empirical tests (Maron and Vilà 2001; Levine et al. 2004).

Here, we focus on two biotic factors that are known to severely limit plant performance and therefore potential invasiveness: interspecific competition (e.g., Harper 1977; Gustafsson and Ehrlen 2003) and insect herbivory (e.g., Louda and Potvin 1995; Louda and 
Rand 2002; Kuijper et al. 2004). For example, established neighboring plants could directly limit the invasiveness of an introduced species if they outcompeted the introduced plant for limited resources (Thébaud et al. 1996; Suding et al. 2004). Alternately, natural enemies, such as herbivores, could reduce the survival, growth and reproduction of the introduced species, reducing plant fitness as well as plant population density and distribution (Louda 1982; Louda and Rodman 1996; Erneberg 1999).

The combined effects of interspecific competition and insect herbivory on introduced plant species performance, although potentially important, are much less explored (Meiners and Handel 2000; Hämback and Beckerman 2003; Lau and Strauss 2005). Competition and herbivory together could reduce individual plant performance and population growth more than each does independently. An interaction between competition and herbivory, leading to biotic resistance, could manifest mainly in three ways. First, if herbivory has a great effect on the growth of the introduced plant species, then the relative competitive ability of the introduced plant may be reduced (Carson and Root 1999). A comparison of introduced versus native species pairs found that introduced plants experienced similar or greater interspecific competition than did native species, at least under some levels of resource availability (Daehler 2003). Second, if competition reduces defense against or tolerance to herbivory by the introduced plant species, then herbivory on introduced plants may lead to reduced fitness. Third, if co-occurring native plants increase relative herbivore abundance, then the introduced plant may receive more damage in association than in isolation, i.e., introduced species may suffer from apparent competition (Holt 1977; Rand 2003).

To experimentally evaluate effects of interspecific competition by established vegetation and herbivory by native insects as biotic resistance to biological invasion, we quantified responses of both the introduced Cirsium vulgare (Savi) Tenore (bull thistle) and its most common co-occurring native congener, C. altissimum (L.) Spreng. (tall thistle), in western tallgrass prairie in eastern $\mathrm{Ne}-$ braska. A native of Eurasia, C. vulgare is now widespread and invasive worldwide (Julien and Griffiths 1998). However, although C. vulgare has been reported in Nebraska for $>200$ years (Kaul et al. 2006), its abundance has remained low, much lower than that of $C$. altissimum (Andersen and Louda 2008). Yet, in eastern Nebraska these two thistles have similar life histories, morphologies, phenologies, and dispersal strategies (Louda and Rand 2002), as well as natural enemies (Takahashi 2006). Comparative field studies between native and introduced congeneric pairs are useful for identifying traits that may promote or limit invasiveness (Mack 1996). While native and introduced congeners share many similarities given their evolutionary history, the few unshared traits provide clues into what might explain differences in performance. For example, if an introduced species has much lower abundance than a co-occurring native congener, then the introduced species may lack traits found in the native that are essential for survival in the introduced range (Mack 1996).

The current study follows from our previous field study (Suwa et al. 2010), which examined effects of competition and herbivory on established rosettes of $C$. vulgare ( $>1$ year old). We found that insect herbivory had strong effects on growth and seed production, but interspecific competition had little effect. Also, no interaction occurred between competition and herbivory on the growth and reproduction of established plants. Since the weak effect of competition contradicted field observations, we hypothesized that established rosettes could already have overcome the major competitive effect. If so, then competition and the interaction between competition and herbivory might be expressed during an earlier life stage. Previous studies have shown that even low levels of herbivory at early stages can severely impair subsequent plant performance (Meiners and Handel 2000), and that interspecific competition can limit seed germination and seedling survival more than rosette growth and survival (Jongejans et al. 2007). Thus, we examined experimental C. vulgare populations from the seed stage to the reproductive stage within the native community context; we evaluated the overall hypothesis that competition and herbivory exerted their major effects, and so imposed biotic resistance, on earlier life stages of this known invasive plant species.

Using this system, we evaluated two specific hypotheses which emerge from the biotic resistance hypothesis. First, we hypothesized that competition from native prairie plants and herbivory by native insects interact to reduce the establishment and regeneration of $C$. vulgare. Second, the reduction imposed would be greater for the introduced C. vulgare than for the native C. altissimum. The second hypothesis, based on field observations (Louda and Rand 2002; Andersen and Louda 2008), is counter to some empirical evidence from other systems (Wolfe 2002; Carpenter and Cappuccino 2005; Liu et al. 2007) and some theoretical work (Elton 1958) which show that introduced plants can have higher performance in a novel habitat than in the native habitat, presumably because they have escaped their natural enemies. While $C$. vulgare may have escaped from its co-evolved enemies from its native range, it has not completely escaped from either generalist or thistle specialist herbivores in the introduced range (Louda and Rand 2002; Takahashi 2006). Field evidence shows that C. vulgare shares the dominant, thistle-feeding insect herbivores with its native congener, $C$. altissimum in eastern Nebraska (Takahashi 2006). In summary, we test 
the effects of biotic resistance, by the resident plant community and by insect herbivores, on introduced C. vulgare as an explanation of the more limited occurrence of the introduced C. vulgare than of the native C. altissimum in tallgrass prairie.

\section{Methods}

\section{Study system}

Bull thistle, C. vulgare, is native to Eurasia, but it is reported to be invasive globally (Julien and Griffiths 1998). Tall thistle, C. altissimum, is native to central and eastern United States, and it is 100 times more frequent than $C$. vulgare on transects in the western tallgrass prairie (Andersen and Louda 2008). Both C. vulgare and C. altissimum are taprooted, monocarpic biennials or short-lived perennials (Guretzky and Louda 1997; Kaul et al. 2006) with similar, late-season flowering phenologies (Louda and Rand 2002). Seeds fall in close proximity to the parent plant, and seed banks are short-lived (Klinkhamer et al. 1988).

The experiment was conducted at Pioneers Park Nature Center, Lancaster County, NE, USA $\left(40^{\circ} 46^{\prime} 34.74^{\prime \prime} \mathrm{N}\right.$, $96^{\circ} 46^{\prime} 43.30^{\prime \prime} \mathrm{W}$; $360 \mathrm{~m}$ elevation), in a tallgrass prairie restoration that started in 1999 from heavily grazed pasture (B. Seth, personal communication). Both thistle species were present in the study area. Vegetation in plots consisted of a mix of native and non-native species typical of prairie in this region. Dominant species were: two native grasses (Schizachyrium scoparium (Michx.) Nash, Andropogon gerardii Vitman), an introduced grass (Bromus inermis Leyss), and a native forb (Conyza canadensis (L.) Cronquist). Vegetation cover was relatively homogeneous and similar among the experimental plots.

The main foliage herbivores on thistle seedlings under the ambient herbivory treatment were: grasshoppers (Melanoplus spp: Orthoptera), Painted Lady butterfly larvae (Vanessa cardui (L.), Lepidoptera: Nymphalidae), and small slugs (Mollusca) (M. Takahashi, personal communication 2006). Meristem damage was mainly caused by: Baris sp. nr. subsimilis Casey (Coleoptera: Curculionidae), Platyptilia carduidactyla (Lepidoptera: Pterophoridae), and Dasineura sp. (Diptera: Cecidomyiidae). The severe damage observed to developing and mature flower heads primarily reflected feeding by a native picture-winged fly Paracantha culta (Wiedemann) (Tephritidae) and three lepidopteran larvae: cosmopolitan artichoke plume moth Platyptilia carduidactyla (Riley) (Lepidoptera: Pterophoridae), native Lobesia carduana (Lepidoptera: Busck) (Tortricidae), and native Homoeosoma eremophasma complex (formerly $H$. stypticellum) (Pyralidae) (Takahashi 2006).

\section{Experimental design and protocol}

\section{Plot establishment}

We experimentally imposed competition and herbivory treatments in an unbalanced factorial design, with more plots in herbivory treatments because we expected high variation in herbivory. We included three levels of competition and two levels of herbivory for each of two species. Within each of six $13.5 \mathrm{~m} \times 7.0 \mathrm{~m}$ blocks, we established 30 plots $(25 \mathrm{~cm} \times 50 \mathrm{~cm})$, spaced $1 \mathrm{~m}$ apart (total $n=180$ plots). Each block was $>30 \mathrm{~m}$ from all other blocks. Since six plots (all in the ambient herbivory treatment) were accidentally sprayed with herbicide, they were removed from the experiment (final $n=174$ plots; number of replicate plots by treatment in Figure 1).

To establish the experimental seedling cohort, we planted 400 locally collected seeds of either $C$. vulgare or C. altissimum in each plot on January 5-10, $2007(n=15$ plots/species/block). Based on published emergence and summer survival (Tenhumberg et al. 2008), we estimated 400 seeds would result in at least ten seedlings per plot, allowing us to quantify plant establishment, growth, survival, and herbivore damage over two growing seasons. Early in the first growing season (May 2-4, 2007), we recorded the number of emerged seedlings; we then standardized plot seedling density between thistle species by thinning (see the Supplementary Material). Post-emergence standardization prevented variation in initial densities between species from confounding the evaluation of the subsequent response to experimental treatment.

\section{Interspecific competition treatments}

We manipulated interspecific competition by altering the cover of ambient vegetation before the experimental seeds were sown (done by November 5, 2006). These three competition treatments were: high (ambient: 65$90 \%$ cover); medium (reduced to $25-35 \%$ cover); and, low (reduced to $0-5 \%$ cover). Ambient plot vegetation cover in the medium- and low-competition treatments was reduced by applying glyphosate (Roundup ${ }^{\circledR}$; Monsanto, St. Louis, MO, USA) at the recommended rate $\left(1.12 \mathrm{~kg}\right.$ a.i. $\left.\mathrm{ha}^{-1}\right)$. To establish the medium-competition (25-35\% cover) treatment, we sprayed small patches (65\% of total area) through $8 \mathrm{~cm}$ diameter holes cut in a regular pattern in a board, distributing the reduction across the plot. To establish the low-competition (0-5\% cover) treatment, we sprayed the entire plot. Treatments were assigned randomly to plots within each block $(n=4$ replicates per treatment per species per block, 24 replicates total per competition treatment per species). Cover levels were maintained by weeding only during 
C. vulgare
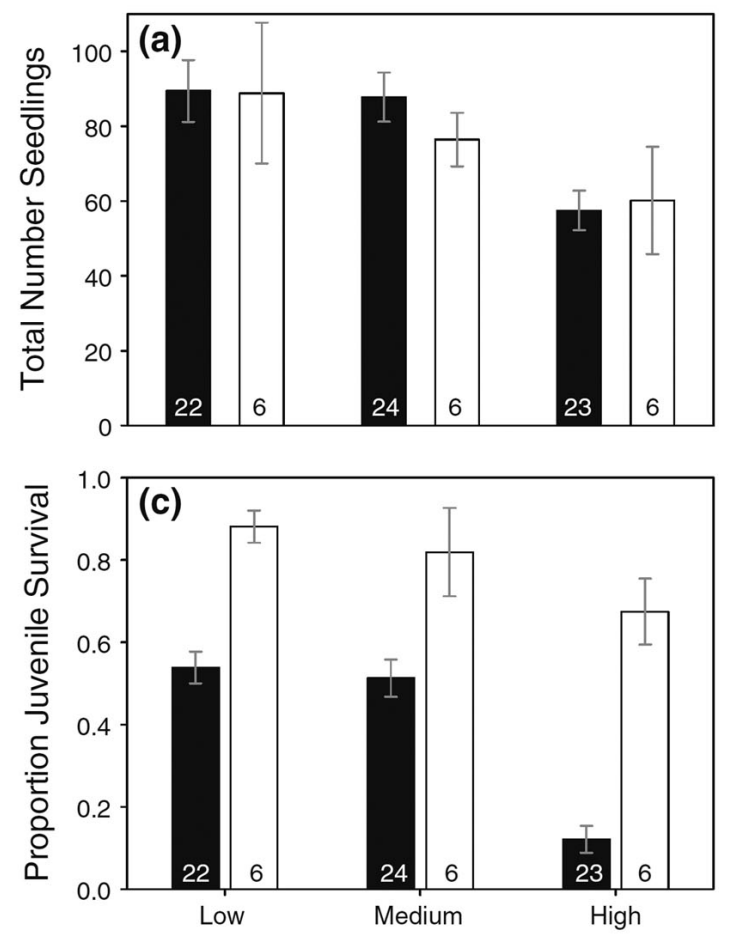

C. altissimum
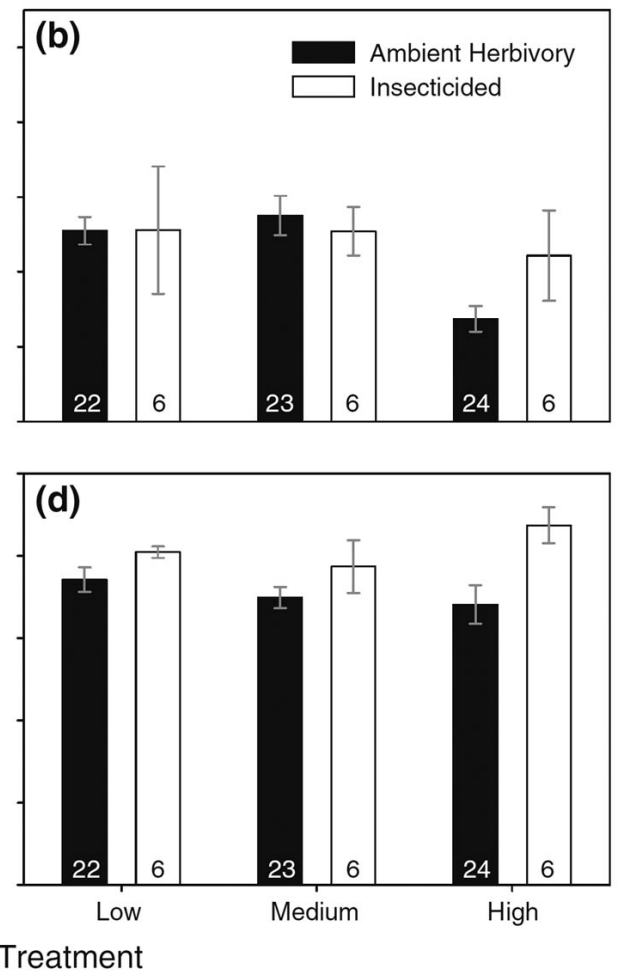

Figure 1. Mean number of seedlings emerging per plot (April 1-October 3, 2007) for the introduced C. vulgare (a) and for the native C. altissimum (b); and total proportion of juveniles surviving per plot (May 5, 2007 and July 3, 2008), including overwinter, for C. vulgare (c) and for C. altissimum (d) by treatment. Mean proportion of juveniles surviving was calculated as the total number of plants per plot in July 2008 divided by the number of seedlings in June 2007, after thinning to standardize densities plus any seedlings that emerged after thinning in 2007. Error bars represent the standard error of the mean (SEM). Numbers inside each bar are sample sizes.

the first growing season (seedling stage, 2007), and not during the second season (juvenile stage, 2008).

Insect herbivory treatments

Insect herbivory was reduced on a subset of the plots in each competition treatment for each species by spraying with the pyrethroid insecticide bifenthrin (Talstar One ${ }^{\circledR}$, FMC Professional Solutions Corp., Philadelphia, PA, USA) ( $n=1$ plot per species per competition treatment per block; total $n=6$ plots per species per competition treatment). The other plots in each competition treatment were sprayed with an equivalent amount of water as a control. We limited the number of replicates in the reduced herbivory treatment to maximize the number of replicates $(n=22-24$ per species per competition treatment) in the ambient (control) herbivory treatment, because previous studies (Suwa et al. 2010) suggested that ambient levels of herbivory varied significantly among plots. Bifenthrin does not contain nitrogen (MSDS ref. no: 82657-04-3116), and it had no direct effect on seedlings of either thistle (Eckberg 2008; Suwa et al. 2010). The insecticide was applied at the recommended concentration $(0.06 \%$ : $7.81 \mathrm{~mL}$ per L water) every 20 days during the first, but not the second, growing season (April 27 to September 15, 2007).

\section{Data collection}

To quantify individual emergence, survival and mortality, all seedlings were marked with toothpicks upon first observation. We counted numbers of surviving, dead, and new seedlings on each census date (biweekly in April, monthly May-October). To quantify seedling growth and leaf herbivory, we tagged ten randomly selected seedlings in each plot (May 5-8, 2007) and measured them monthly (to August 17). Seedling success was represented by: total number of seedlings emerging (April 1 to October 3, 2007), seedling survival over the first growing season, and total juvenile survival cumulative over both seasons. Total juvenile survival was measured as the number of plants alive at the end of the second season (late July 2008) divided by the total number of seedlings after thinning plus any seedlings that subsequently emerged (June-October 2007). 
On each census date, we recorded the total number of leaves and number of leaves with $>12.5 \%$ of the area damaged to develop a ratio of leaf damage. We chose this level of damage as our criterion because average rates of defoliation are 5-15\% (Crawley 1989). We also recorded the presence/absence of severe herbivore damage to root crown meristems. Since the frequency of meristem damage was very low overall (average was $<10 \%$ of tagged seedlings per plot with evidence of meristem feeding), meristem damage is reported in the Supplementary Materials (Figure S1).

To quantify subsequent overall growth and reproduction, we harvested all aboveground thistle biomass per plot, including flower heads, near the end of the second season (July 29-August 1, 2008). The biomass was dried at $65^{\circ} \mathrm{C}$ for seven days and weighed. Biomass samples from eight plots were lost; however, all of these missing samples were from the ambient herbivory treatment ( $>20$ replicates remained), making it unlikely that the missing data affected the direction of the results (see below). If a tagged plant died prior to harvest in August 2008 , then the plant closest to the tagged plant was harvested ( $n \leq 10$ per plot). Biomass of tagged plants was averaged for analysis. We also counted the total number of flower heads.

\section{Statistical analyses}

We used ANOVA to test effects of competition and herbivory treatments on: ratio of leaf damage, seedling and juvenile survival, and juvenile size (SAS Proc GLM and Proc MIXED; v.9.1.3, SAS Institute, 2007). Juvenile size was natural-log transformed to meet assumptions for ANOVA. In each analysis, herbivory, competition and thistle species were included as fixed factors, and block was a random factor. All main effects and interaction terms were included in the model. When interaction terms were significant, we used Tukey's honestly significant difference test (HSD) to evaluate differences among treatment combinations.

We used two steps to quantify the effects of competition and herbivory treatments on subsequent reproduction. First, we tested treatment effects on the occurrence (presence/absence) of any mature flower heads on the tagged plants using a generalized linear model with a logistic ANOVA (SAS Proc GENMOD, v.9.1.3, SAS Institute 2007). We again treated leaf herbivory, competition, and thistle species as fixed factors and block as a random factor. Second, for tagged plants that matured at least one flower head, we analyzed treatment effects on the total number of flower heads matured per plot (ANOVA on natural-log transformed data); this analysis reflects cumulative effects of competition, herbivory, or both on flowering success.

\section{Results}

Overall, interspecific competition and insect herbivory independently, and sometimes interactively, significantly reduced both recruitment and subsequent reproduction by the introduced C. vulgare.

\section{Interspecific competition for introduced C. vulgare}

High levels of interspecific competition reduced the total number of $C$. vulgare seedlings that emerged successfully (Figure 1a: $F_{2,76}=4.88, P=0.01$; $P_{\text {High vs. Low }}=0.01, P_{\text {High vs. Medium }}=0.067 ;$ Tukey's HSD). Competition at the high, ambient level also significantly reduced both seedling survival (not shown) and juvenile survival (Figure 1c) of C. vulgare relative to both the medium and the low levels (seedling survival: $F_{2,76}=26.47, P<0.001 ; P_{\text {High vs. Low }}<0.001$, $P_{\text {High vs. Medium }}<0.001$; juvenile survival: $F_{2,76}=9.69$, $P<0.001 ; P_{\text {High vs. Low }}=0.001, P_{\text {High vs. Medium }}<0.001$; Tukey's HSD). Seedling and juvenile survival of $C$. vulgare averaged between five- and six-fold higher at both the medium and low levels of interspecific competition than at the high level of competition (Figure 1c). Leaf damage on C. vulgare did not differ among the competition treatments (Figure 2a).

High competition significantly reduced subsequent growth of $C$. vulgare. High-competition plots had lower vegetative biomass per plant than did those in low- or medium-competition treatments (Figure 3a; $F_{2,70}=23.39$, $P<0.001 ; P_{\text {High vs. Low }}<0.001, P_{\text {High vs. Medium }}<0.001$; Tukey's HSD).

Further, high competition reduced reproduction, specifically the proportion of $C$. vulgare plants that matured at least one flower head (Figure $3 c ; \chi_{1}^{2}$ Low vs. High $=15.02$, $P=0.001 ; x_{1}{ }^{2}$ Medium vs. High $\left.=7.09, P=0.008\right)$. However, the number of flower heads produced among tagged plants per plot was not significantly reduced by competition (Figure $3 \mathrm{e} ; F_{2,16}=1.98, P=0.171$ ), although this result was based on a small sample size, because only two plots in the high-competition treatment had plants that matured at least one flower head (Figure 3e). Overall, high levels of competition reduced the probability of flowering within two years, but not the number of flower heads that matured if a plant reached flowering.

\section{Insect herbivory on introduced C. vulgare}

The insecticide treatment effectively reduced leaf damage on $C$. vulgare $\left(F_{1,70}=13.37, P<0.001\right.$, Figure $\left.2 a\right)$. Although herbivory had no effect on $C$. vulgare seedling emergence (Table 1), the experimental reduction of ambient herbivory on seedlings increased the survival of all $C$. vulgare juveniles by $95 \%$ on average $\left(F_{1,70}=48.45\right.$, $P<0.001)$. 


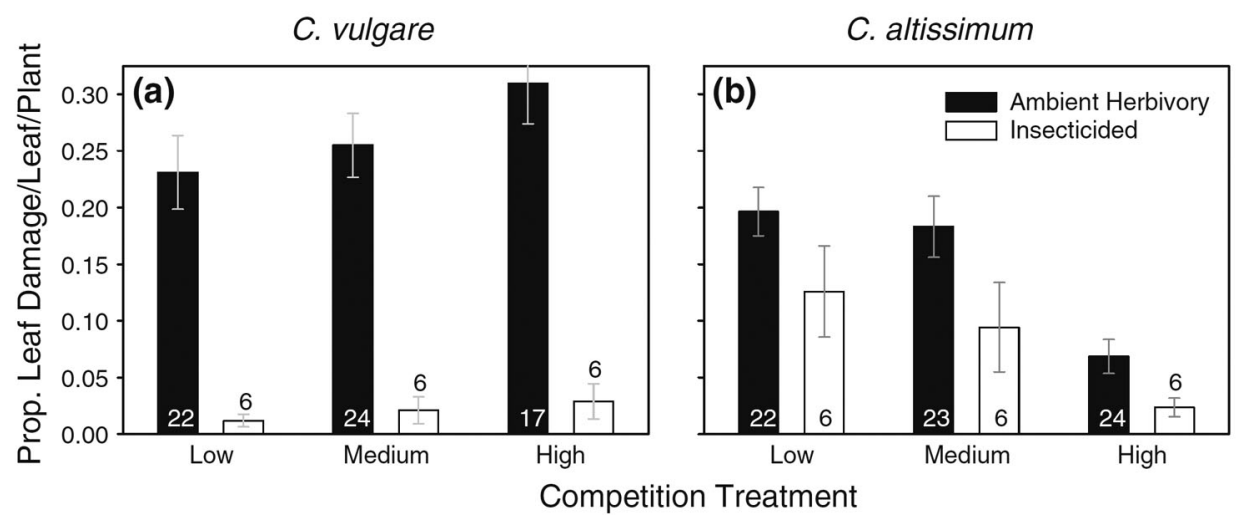

Figure 2. Proportion of leaves per seedling plant per plot with major leaf area damage ( $\geq 12.5 \%)$ for C. vulgare (a) and C. altissimum (b) at the end of the growing season (August 2007). Error bars represent standard errors of the mean (SEM). Numbers inside the bars are sample sizes. The main effect of herbivory treatment was significant $\left(F_{1,151}=51.44, P<0.001\right)$, but the main effects of competition and species were not $\left(C: F_{2,151}=0.96, P=0.384 ; S: F_{1,151}=0.16, P=0.208\right)$; some two-way treatment interactions were also significant $\left(\mathrm{C} \times \mathrm{S}: F_{2,151}=5.01, P=0.008 ; \mathrm{H} \times \mathrm{S}: F_{1,151}=16.40, P<0.001\right)$.
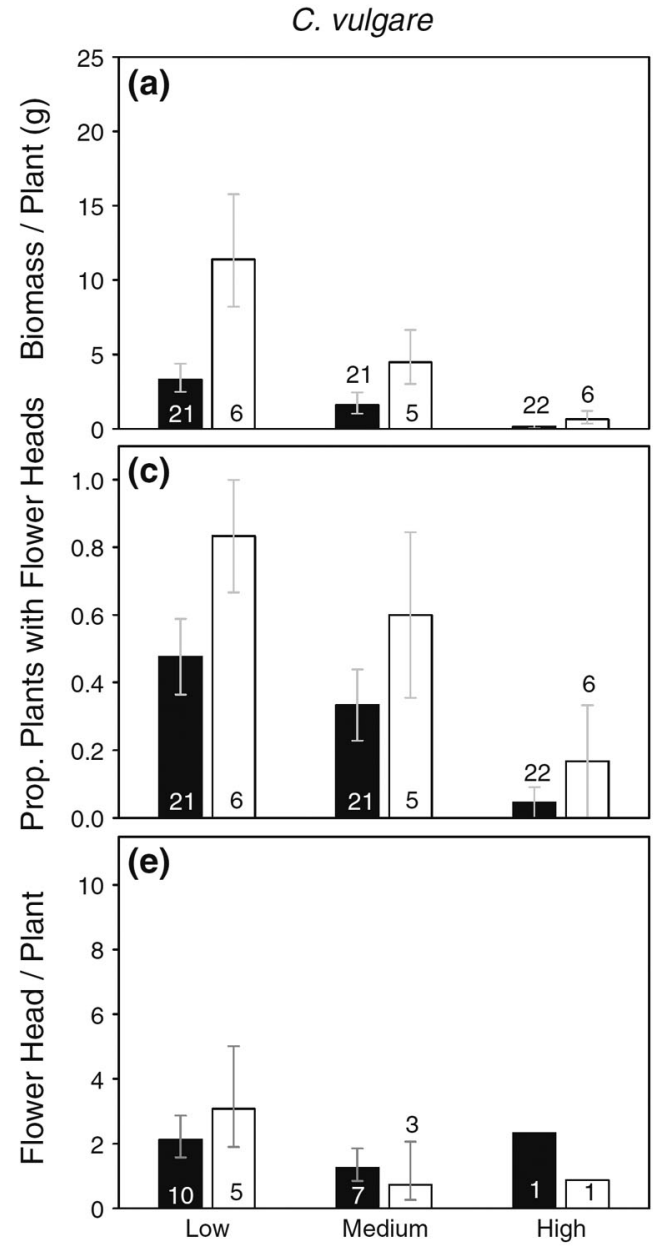
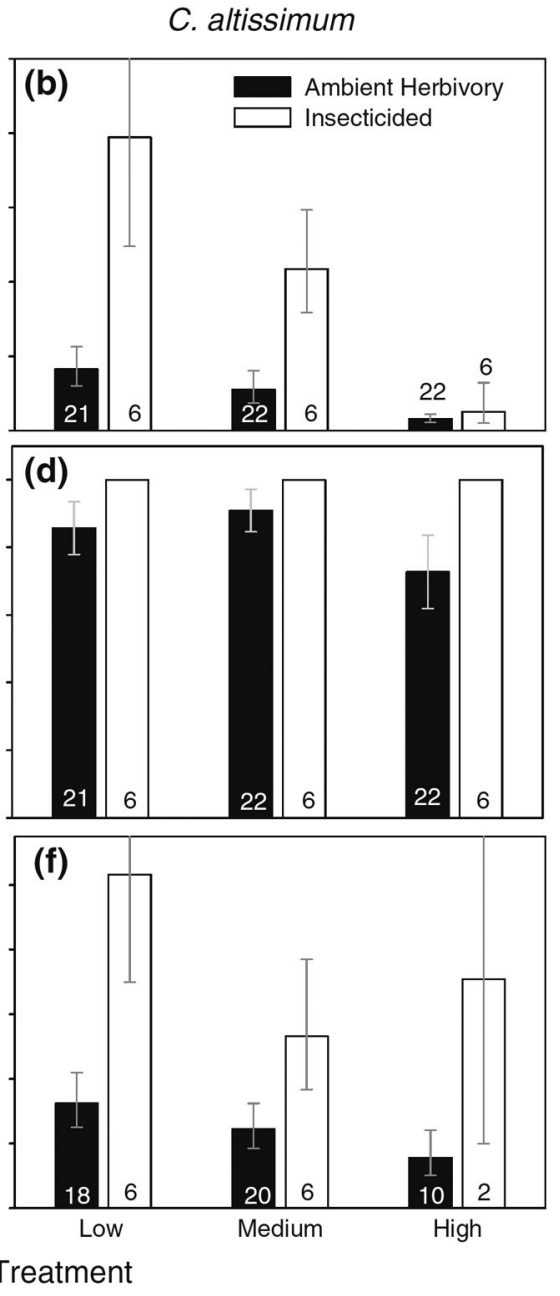

Figure 3. Mean vegetative thistle biomass per tagged plant per plot for C. vulgare (a) and for C. altissimum (b); mean proportion of tagged plants per plot with at least one flower head for C. vulgare (c) and for C. altissimum (d); and, mean number of flower heads per tagged plant per plot for C. vulgare (e) and for C. altissimum (f) at the end of the second growing season (August 2008), by treatment. Error bars represents standard errors of the mean (SEM). Numbers inside the bars are sample sizes.
The ambient level of insect herbivory also significantly reduced the growth of C. vulgare (Figure 3). Herbivory on $C$. vulgare reduced the vegetative biomass of tagged plants by $40.3 \%$ (Figure 3a; $F_{1,70}=20.20, P<0.001$ ).

Further, the ambient level of herbivory reduced subsequent reproduction by decreasing the average num- ber of plants that produced at least one flower head by $53.6 \%$ (Figure $3 c ; x_{1}^{2}=4.52, P=0.034$ ). This effect of herbivory was independent of competition treatment. However, among those plants that produced at least one flower head, seedling herbivory did not further alter the number of flower heads that matured per $C$. vulgare 
Table 1. Analysis of variance (ANOVA) of plant response to treatment in total seedling emergence (April 1, 2007-July 3, 2008), seedling survival (May 5-October 3, 2007), and total (cumulative) juvenile survival, including overwinter (May 5, 2007-July 3, 2008)

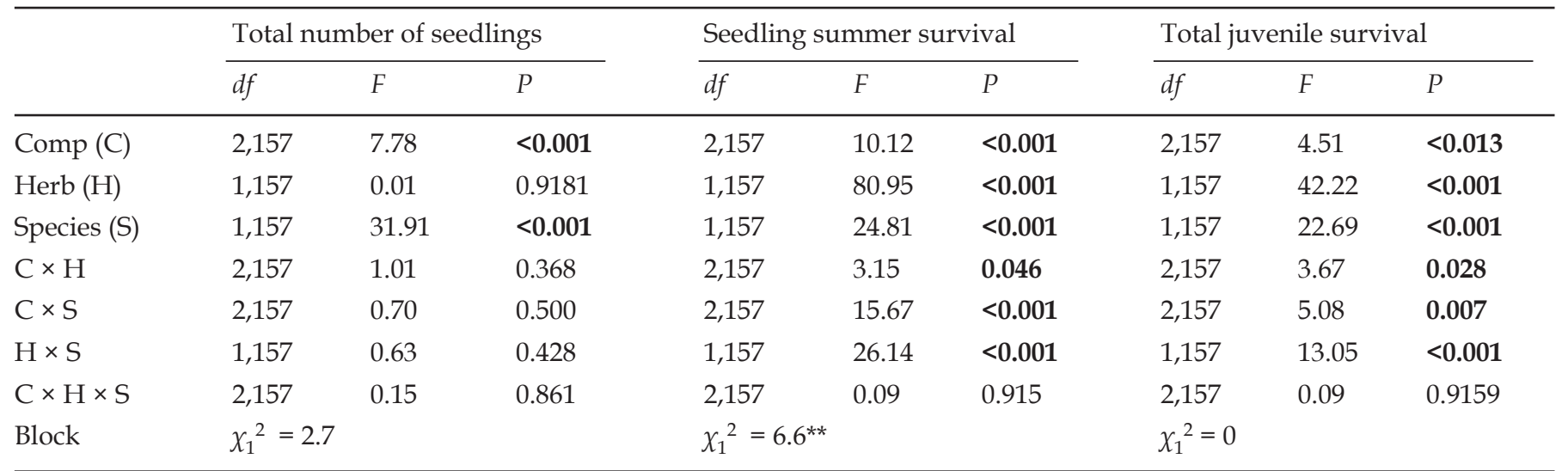

Seedling survival was calculated as the number of seedlings at the end of the season divided by the number of seedlings after initial thinning (June 4-14, 2007) plus the number of new seedlings that emerged after thinning. Fixed factors were: competition treatment $(\mathrm{C})$, herbivory treatment $(\mathrm{H})$, and species $(\mathrm{S})$; blocks were treated as a random factor and examined using the likelihood ratio test, which approximates a chi-square distribution with one degree of freedom. Significant differences are indicated by bold or by ${ }^{* *} P<0.01$.

plant (Figure $3 \mathrm{e} ; F_{1,16}=0.28, P=0.602$ ). This result again was based on a small sample size, since only two plots in the high-competition treatment produced any tagged plants that matured at least one flower head (Figure 3e). Overall, herbivory on seedlings had a significant negative effect both on subsequent C. vulgare biomass and on the probability of maturing at least one flower head.

\section{Interaction of interspecific competition and herbivory for C. vulgare}

Herbivory reduced plant survival more in the highcompetition treatment than the low-competition treatment for C. vulgare. Specifically, although the effect of herbivory $(\mathrm{H}+)$ on seedling emergence and seedling performance was consistent across competition treatments (Figures $1 \& 3$ ), herbivory reduced cumulative plant survival to the end of the second growing season more under high than under low competition $\left(P_{\mathrm{H}+\text { Low vs.H+/High }}<0.001\right.$; Tukey's HSD).

\section{Comparison of responses by introduced C. vulgare vs. native C. altissimum}

Overall, the negative effects of insect herbivory and interspecific competition were greater for $C$. vulgare than for its co-occurring native congener, $C$. altissimum. Although $C$. vulgare had higher emergence than $C$. altissimum (Figure 1a, b), both seedling survival and cumulative juvenile survival (Figure 1c, d) were significantly lower for C. vulgare than for C. altissimum (Table $1, P$ $<0.0001$ ).

Ambient levels of leaf damage were higher on C. vul- gare than C. altissimum (Figure 2; $F_{1,125}=24.43, P<0.001$ ). Competition level did not alter the high proportion of damaged leaves on C. vulgare under ambient herbivory, whereas herbivory on C. altissimum was higher at lowand medium-competition levels than at high-competition $\left(\mathrm{C} \times \mathrm{S} F_{2,151}=5.01, P<0.008 ; P_{\text {High vs. Low }}<0.001\right.$, $P_{\text {High vs. Medium }}<0.003$; Tukey's HSD). Finally, while the insecticide treatment effectively reduced herbivory for both species (Figure 2), this treatment reduced the proportion of leaves per plant with major leaf area damage $(>12.5 \%)$ more for C. vulgare than for C. altissimum (Figure $\left.2 ; F_{1,151}=16.40, P<0.001\right)$.

Insecticide treatment also increased the survival and growth of $C$. vulgare more than C. altissimum (Figures 1 $\& 3)$. The proportion of juveniles surviving ambient herbivory was lower for $C$. vulgare than $C$. altissimum, and insecticide treatment increased the survival of $C$. vulgare more than C. altissimum (Figure 1c, d). Although only marginally significant, average plant biomass appeared lower for $C$. vulgare than for $C$. altissimum under ambient herbivory (Table 2), and insecticide treatment led to a proportional increase in biomass for both species (Figure $3 a, b)$.

Finally, effects of competition and herbivory on reproduction differed between the two species. The proportion of plants flowering per plot in the second year was lower for $C$. vulgare than C. altissimum (Figure 3c, d; $\left.x_{1}^{2}=36.84, P<0.001\right)$. Also, the number of flower heads that matured per plot was significantly lower for $C$. vulgare than for C. altissimum under ambient herbivory (Table 2; $F_{1,72}=4.35, P=0.041$ ). Insecticide application, however, did not increase the number of heads that matured as much for C. vulgare as C. altissimum (Figure 3e, f). 
Table 2. Analysis of variance (ANOVA) of plant response to treatment in vegetative biomass per plant and average number of mature flower heads per tagged plant per plot (July 2008).

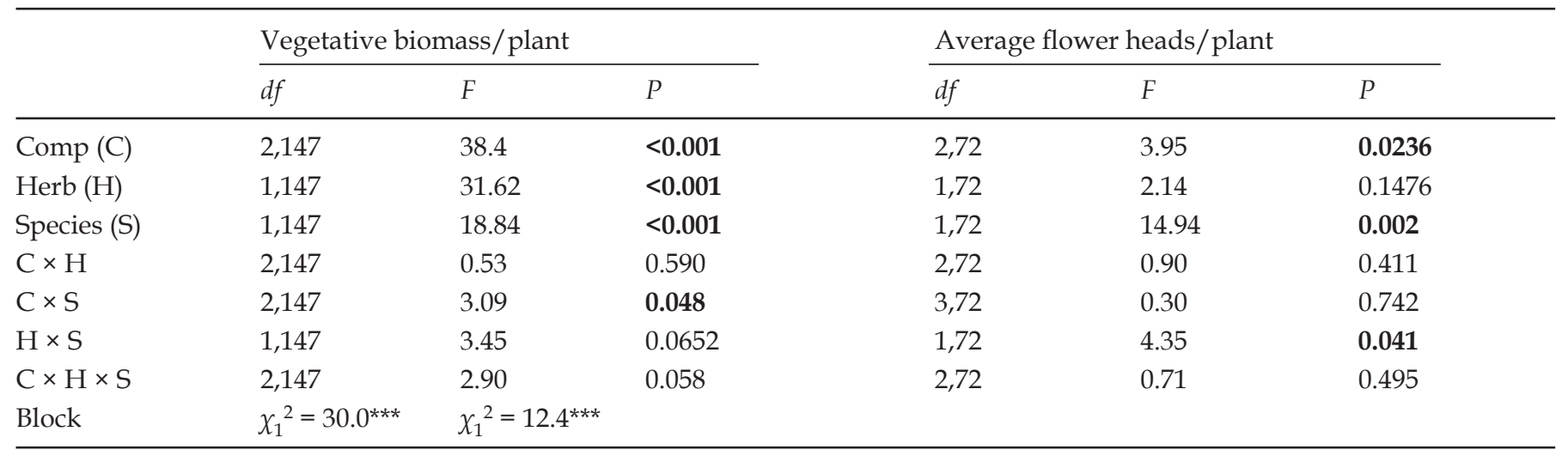

Fixed factors were: competition treatment $(\mathrm{C})$, herbivory treatment $(\mathrm{H})$, and species $(\mathrm{S})$; blocks were treated as a random factor and examined using a likelihood ratio test, which approximates a chi-square distribution with one degree of freedom. Significant differences are indicated by bold or by ${ }^{* * *} P<0.001$.

\section{Discussion}

The experimental results thus indicate that in spite of an initial advantage in recruitment, $C$. vulgare performance was reduced (and more severely reduced than $C$. altissimum) by cumulative insect herbivory, and that effect was amplified at high, ambient competition. Thus, as predicted under the biotic resistance hypothesis, interspecific competition and native insect herbivory significantly reduced both survival and subsequent reproduction for the introduced species C. vulgare, and did so more than for the ecologically similar and co-occurring native congener $C$. altissimum. These results add to the accumulating body of experimental work demonstrating that both interspecific competition (e.g., Kuijper et al. 2004; Seastedt and Suding 2007; Going et al. 2009) and insect herbivory (e.g., Louda and Rand 2002; Jacobs et al. 2006) often significantly reduce the survival, growth, and reproduction of introduced plant species.

We found that interspecific competition from the ambient native plant community was a stronger component of biotic resistance to establishment, growth (biomass) and reproduction for the introduced C. vulgare than for the native $C$. altissimum. The significant interspecific competitive effect was mediated through a reduction in seedling establishment and early survival, and it also affected plant size and the proportion of plants with at least one flower head. These data are consistent with other recent studies (e.g., Kuijper et al. 2004; Seastedt and Suding 2007; Going et al. 2007) showing that interspecific competition, especially at early life stages, can reduce plant invasiveness.

Results also show that insect herbivory on seedlings and juveniles strongly limited the regeneration of introduced C. vulgare, in contrast with expectations based on the enemy release hypothesis (Elton 1958). While C. vul- gare in western tallgrass prairie occurred without specialist predators from its native range, it encountered a new suite of natural enemies, a thistle-feeding suite that was pre-adapted to feed on C. vulgare. Prior work has demonstrated that C. vulgare shared $96 \%$ of the native, thistle-feeding arthropod fauna found on C. altissimum, including the most abundant thistle specialists (Takahashi 2006). Further, consistent with the biotic resistance hypothesis, we found that the average level of cumulative ambient herbivory was greater on the introduced $C$. vulgare than on C. altissimum, despite the close phylogenetic relationship and the strong ecological similarities of these two thistles.

One hypothesis to explain the net outcome of this comparison of experiments is that $C$. vulgare is not as well adapted as the native C. altissimum either to defend against herbivory or to tolerate the level of herbivory imposed by native thistle-feeding insects in tallgrass prairie. Ambient foliage herbivory was generally higher on C. vulgare than on C. altissimum, suggesting lower resistance by the introduced thistle. Also, in the face of the ambient level of herbivory on both species, fewer flower heads were matured by C. vulgare than C. altissimum, suggesting that the introduced thistle was less tolerant of herbivory. In addition, although not all the thistles bolted and flowered in the second year, the number of immature plants remaining per plot did not differ between species nor between herbivory treatments; the only difference was a higher number of small plants under high competition with reduced herbivory treatment (Supplementary Materials, Figure S2). Note that the individuals under this treatment were very small (Fig 3a, b); only $5 \%$ of those plants had $>5$ leaves (data not shown). Small thistle rosettes have a low probability of successful survival and subsequent reproduction (Louda and Potvin 1995; Rose et al. 2005). Thus, it is un- 
likely that the immature plants surviving at the end of the experiment (2008) would have altered the patterns reported here.

Although relatively few studies quantitatively compare the effect of insect herbivory on an introduced species and a native congener, our results conflict with most of the studies available to date. For example, a field experiment using 15 taxonomic pairs of introduced and native old-field plant species showed that introduced plants received significantly less insect herbivory and attack by soil pathogens than did their native congeners (Agrawal et al. 2005). Similarly, introduced Eugenia spp. (Myrtaceae) in South Florida experienced less insect herbivory than did their native relatives (Liu et al. 2007). Our study, in contrast, showed a greater effect of insect herbivory, by a pre-adapted native insect herbivory guild, on early survival, plant growth, and subsequent reproduction of the introduced plant than its cooccurring native congener.

Based on predictions from the biotic resistance hypothesis and prior evidence for this system, along with previous empirical work showing synergistic effects of competition and herbivory (Elton 1958; Meiners and Handel 2000; Lau and Strauss 2005), we hypothesized that the combined effects of competition and herbivory would be more negative for $C$. vulgare than for the native $C$. altissimum. In fact, we found evidence of synergism in these effects of competition and herbivory, especially on seedling survival and total, cumulative juvenile survival for both species. However, the magnitude of the synergistic effect did not differ dramatically between the two species. Thus, synergism between competition and herbivory cannot fully explain the lower abundances of $C$. vulgare, compared with those of the co-occurring native $C$. altissimum, recorded in western tallgrass prairie (Andersen and Louda 2008). Instead, differences in the abundances of these two thistles (Andersen and Louda 2008) can be explained by the greater direct, independent effects of high levels of both interspecific competition and insect herbivory on C. vulgare than C. altissimum.

This outcome provides experimental evidence of mechanisms of interaction affecting these thistles that is consistent with, and extends our understanding of, the ecology of this system. Previous work showed that insect floral herbivory strongly reduced seed production of C. vulgare (Louda and Rand 2002), and that propagule input can influence local density of both species (Eckberg 2008; Russell et al. 2010). Further, two relevant demographic models, specifically a matrix model for C. vulgare (Tenhumberg et al. 2008) and an integral projection model for C. altissimum (Russell et al. 2010), predict that the population dynamics of these thistles are strongly limited by both insect herbivory and interspecific competition. This study presents new experimental results that help explain previous stud- ies. It also provides strong empirical support for the idea that herbivory and competition are significant factors in the lower densities of C. vulgare than C. altissimum in western tallgrass prairie (Andersen and Louda 2008). The next step is to use these results to compare the population growth of these species in order to determine the extent to which the biotic resistance hypothesis is supported at the population level (T. Suwa et al. unpublished).

In sum, the experiment reported here is one of the few quantitative tests of the biotic resistance hypothesis. Independent, cumulative effects of both competition exerted by established vegetation and foliage herbivory imposed by native insects, plus some interaction between these processes, limited seedling establishment, juvenile survival, juvenile growth, and subsequent reproduction by the introduced $C$. vulgare, and did so more strongly than on the co-occurring, ecologically similar, native $C$. altissimum. Thus, this study represents a case that highlights the importance of biotic interactions in resistance to biological invasion. Results indicate that interactions with native communities can constrain an incipient biological invasion.

Acknowledgments - We thank J. A. Lau, T.E.X. Miller, D. Pilson, J. Stubbendieck, M. Takahashi, two anonymous reviewers for Oecologia, and the Associate Editor, D. Pyke, for their constructive advice and suggestions. We also thank M. Mellon, N. West, and K. Webbink for field assistance. We greatly appreciate the encouragement and support of B. Seth at the Pioneers Park Nature Center site. Support was provided by a J. E. Weaver Grant from The Nature Conservancy-Nebraska Chapter, a John Davidson Scholarship, and grants from the School of Biological Sciences at University of Nebraska-Lincoln to T. Suwa, as well as NSF-DEB 0532018 and USDA NRI-200535320-15379 grants for thistle research to F. L. Russell and S. M. Louda.

\section{References}

Agrawal AA, Kotanen PM, Mitchell CE, Power AG, Godsoe W, Klironomos J (2005) Enemy release? An experiment with congeneric plant pairs and diverse above- and belowground enemies. Ecology 86:2979-2989

Andersen CP, Louda SM (2008) Abundance of and floral herbivory on exotic bull thistle versus native tall thistle in western tallgrass prairie. In: Proceedings of 20th North American prairie conference 20:33-50

Carpenter D, Cappuccino N (2005) Herbivory, time since introduction and the invasiveness of exotic plants. J Ecol 93:315-321

Carson W, Root R (1999) Top-down effects of insect herbivores during early succession: influence on biomass and plant dominance. Oecologia 121:260-272

Crawley MJ (1989) Insect herbivores and plant population dynamics. Ann Rev Entomol 34:531-564 
Daehler C (2003) Performance comparisons of co-occurring native and alien invasive plants: implications for conservation and restoration. Annu Rev Ecol Syst 34:183-211

Eckberg J (2008) Native insect herbivory on invasion dynamics of Cirsium vulgare (bull thistle) (MS thesis). University of Nebraska-Lincoln, Lincoln

Elton CS (1958) The ecology of invasions by animals and plants. Wiley, New York

Erneberg M (1999) Effects of herbivory and competition on an introduced plant in decline. Oecologia 118:203-209

Going B, Hillerislambers J, Levine J (2009) Abiotic and biotic resistance to grass invasion in serpentine annual plant communities. Oecologia 159:839-847

Guretzky J, Louda SM (1997) Evidence for natural biological control: insects decrease survival and growth of a native thistle. Ecol Appl 7:1330-1340

Gustafsson C, Ehrlen J (2003) Effects of intraspecific and interspecific density on the demography of a perennial herb, $\mathrm{Sa}$ nicula europaea. Oikos 100:317-324

Hämback P, Beckerman A (2003) Herbivory and plant resource competition: A review of two interacting interactions. Oikos 101:26-37

Harper JL (1977) Population biology of plants. Academic, London

Holt RD (1977) Predation, apparent competition, and the structure of prey communities. Theor Popul Biol 12:197-229

Jacobs JS, Sing SE, Martin JM (2006) Influence of herbivory and competition on invasive weed fitness: Observed effects of Cyphocleonus achates (Coleoptera: Curculionidae) and grassseeding treatments on spotted knapweed performance. Environ Entomol 35:1590-1596

Jongejans E, Skarpaas O, Tipping PW, Shea K (2007) Establishment and spread of founding populations of an invasive thistle: The role of competition and seed limitation. Biol Invasions 9:317-325

Julien MH, Griffiths MW (1998) Biological control of weeds: A world catalog of agents and their target weeds, 4th edn. CABI-Bioscience, Wallingford

Kaul RB, Sutherland DM, Rolfsmeier SB (2006) The flora of Nebraska. School of Natural Resources. Institute of Agriculture and Natural Resources, University of NebraskaLincoln, Lincoln

Klinkhamer PGL, De Jong TJ, van der Meijden E (1988) Production, dispersal and predation of seeds in the biennial Cirsium vulgare. J Ecol 403-414

Kuijper DPJ, Nijhoff DJ, Bakker JP (2004) Herbivory and competition slow down invasion of a tall grass along a productivity gradient. Oecologia 141:452-459

Lau JA, Strauss SY (2005) Insect herbivores drive important indirect effects of exotic plants on native communities. Ecology 86:2990-2997

Levine JM, Adler PB, Yelenik SG (2004) A meta-analysis of biotic resistance to exotic plant invasions. Ecol Lett 7:975-989

Liu H, Stiling P, Pemberton RW (2007) Does enemy release matter for invasive plants? Evidence from a comparison of insect herbivore damage among invasive, non-invasive and native congeners. Biol Invasions 9:773-781
Louda SM (1982) Reduction in plant recruitment by flower and seed feeding insects. J Ecol 70:43-54

Louda SM, Potvin MA (1995) Effect of inflorescence-feeding insects on the demography and lifetime of a native plant. Ecology 76:229-245

Louda SM, Rand TA (2002) Native thistles: Expendable or integral to ecosystem resistance to invasion? In: Kareiva P, Levin SA, eds., The importance of species: Perspectives on expendability and triage. Princeton University Press, Princeton, pp 5-15

Louda SM, Rodman JE (1996) Insect herbivory as a major factor in the shade distribution of a native crucifer (Cardamine cordifolia A. Gray, Bittercress). J Ecol 84:229-237

Mack RN (1996) Predicting the identity and fate of plant invaders: Emergent and emerging approaches. Biol Conserv 78:107-121

Maron JL, Vilà M (2001) When do herbivores affect plant invasion? Evidence for the natural enemies and biotic resistance hypotheses. Oikos 95:361-373

Meiners SJ, Handel SN (2000) Additive and nonadditive effects of herbivory and competition on tree seedling mortality, growth, and allocation. Am J Bot 87:1821

Rand TA (2003) Herbivore-mediated apparent competition between two salt marsh forbs. Ecology 84:1517-1526

Rose KE, Louda SM, Rees M (2005) Demographic and evolutionary impacts of native and invasive insect herbivores: A case study with Platte thistle, Cirsium canescens. Ecology $86: 453-465$

Russell FL, Rose KE, Louda SM (2010) Seed availability and insect herbivory limit recruitment and adult density of native tall thistle. Ecology 91:3081-3093

Seastedt TR, Suding KN (2007) Biotic constraints on the invasion of diffuse knapweed (Centaurea diffusa) in North American grasslands. Oecologia 151:626-636

Suding KN, LeJeune KD, Seastedt TR (2004) Competitive impacts and responses of an invasive weed: Dependencies on nitrogen and phosphorus availability. Oecologia 141:526-535

Suwa T, Louda SM, Russell FL (2010) No interaction between competition and herbivory in limiting introduced Cirsium vulgare rosette growth and reproduction. Oecologia 162:91-102

Takahashi M (2006) Insect community composition in ecological resistance to invasiveness of bull thistle in eastern Nebraska (MS thesis). University of Nebraska-Lincoln, Lincoln

Tenhumberg B, Louda SM, Eckberg JO, Takahashi M (2008) Monte Carlo analysis of parameter uncertainty in matrix models for the weed Cirsium vulgare. J Appl Ecol 45:438-447

Thébaud C, Finzi AC, Affre L, Debussche M, Escarre J (1996) Assessing why two introduced Conyza differ in their ability to invade Mediterranean old fields. Ecology 77:791-804

Williamson M, Fitter A (1996) The varying success of invaders. Ecology 77:1661-1666

Wolfe LM (2002) Why alien invaders succeed: Support for the escape-from-enemy hypothesis. Am Nat 160:705 